\title{
Soil Pressure Analysis of Subway Tunnel Across Ground Fissures
}

\author{
Yuan Liqun ${ }^{1, a}$, Liu Nina²and Yang $\mathrm{Mi}^{3}$ \\ ${ }^{1}$ School of Architecture and Civil Engineering, Liaocheng University; Liaocheng 252059, Shandong, \\ China; \\ 2 School of Geology Engineering and Surveying, Chang' an University; Xi' an 710054, Shaanxi, \\ China; \\ aliqunyuan@163.com
}

\begin{abstract}
Keywords: Metro Tunnel; Load; Ground Fissure; Soil Pressure
Abstract: Based on the similarity theory, the subway tunnel - across ground fissures formation dynamic interaction model test was designed. Through the analysis of the model test results, soil pressure and the contact pressure of different forms of piecewise horseshoe subway tunnel under the train load were system studied. Based on the related experimental data analysis, the following conclusion can be learned: when section tunnel did not fall, the ground soil pressure of surrounding rock and integral phase is similar, but after activities led to the decrease of the plate on the ground fissures, the soil pressure value and the overall comparatively large difference; Section tunnel compared to the original static earth pressure is increased; Sectional tunnel with integral tunnel close to the contact pressure distribution regularity, but caused by ground fissure activity on plate, after falling in the upper plate Y1 series on earth pressure caused by the formation escapes the numerical are larger than in the footwall Y2.
\end{abstract}

\section{Introduction}

In recent years, through the study of disaster prevention measures of subway tunnel structure under ground fissures environment, a number of important problems in Xi'an subway construction have been solved. However, as a result of construct subway in the ground fissure area is unprecedented in the history of subway construction. There are many important scientific issues need to be further explored. Dynamic interaction and vibration effects control problems of metro tunnel and surrounding rock is one of the problems. Wang Xin and others take Xi'an Metro Line 2 as background, establish a numerical model of tunnel dynamic interaction with the surrounding soil to research vibration response of train - track - ground. Zhang meicong studies in terms of load, soil parameters and other aspects, studies stress analysis of tube sheet in usual ways. Currently, subway tunnel dynamic response analysis is mostly based on the measured data, mainly for the surface buildings , dynamic response of lining structure and surroundings impact. Once the subway project is completed, it is very difficult to conduct field test of soil pressure of surrounding rock and soil, and the contact pressure of the tunnel lining structure.

The article based on similar theory designs a medal test of across ground fissures metro tunnel ground dynamic interaction. Studies surrounding rock pressure and the contact pressure of the surrounding rock and tunnel lining under the train load across ground fissures in different segments form a horseshoe subway tunnel by analyzing the results of the model test systems.

\section{Model Test Introduction}

According to <Xi'an ground fissures site investigation and engineering design specification>

(DBJ61-2006), define primary deformation range of ground fissure, in accordance with the ratio of $1: 20$, the size of model box is $2 \mathrm{~m} \times 1.6 \mathrm{~m} \times 1.2 \mathrm{~m}$.Horseshoe-shaped tunnel model and test platform dimensions shown in Figure 1 and Figure 2.Reference 1 describes similar relations and the value of related parameters of model test in details.

Simulate the drop of cracks on the disc by the descent of the platform. Right side of the platform as a stable fracture to the lower plate, left side as higher plate of crack. And to make use of the jack on the 
disk to do the appropriate motion. Make use of combination of $\mathrm{AD}$ and $\mathrm{BC}$ to analog subway and ground fissures quadrature working conditions. A combination of $\mathrm{AC}$ and $\mathrm{BD}$ can be simulated to crack the case of the subway and skew $60^{\circ}$ and $30^{\circ}$, respectively. Xi'an Metro Line 2 is a six cars marshaling, the train wheel load is $p_{0}=160 \mathrm{kN}$.simplify the load of model base to a single frequency half sine load. Assuming that the traffic load of subway is:

$$
F(t)=\frac{p_{0}}{2}[1+\sin (2 \pi f t-\pi / 2)]
$$

Loads of different frequencies applied to the track, In order to make the load can be evenly delivered to two parallel tracks, test uses TST-2 electromagnetic exciter to apply through two balancing method.

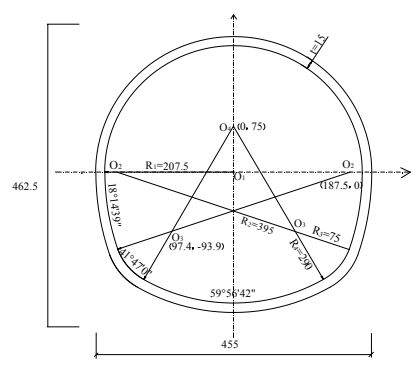

Fig.1 A cross-sectional view of the $U$ shaped tunnel

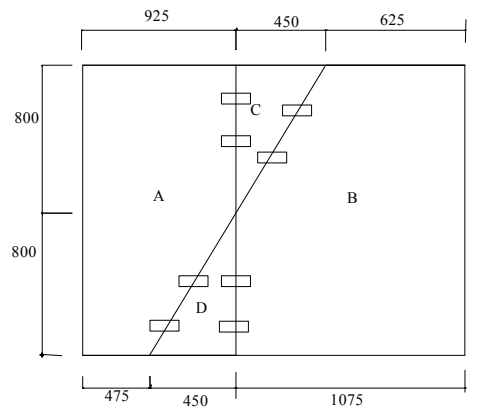

Fig.2 Figure of the model bottom plate

\section{Earth pressure analysis of surrounding rock and soil}

Test uses integrated, two-stage and three-stage tunnel three kinds of tunnel type.Among them ,integral tunnel crosses ground fissure in the overal tunnel.there is no seams nearby crack. Two-stage tunnel off in two parts in the position of cracks.the position of ground fissure is the joint of tunnel; The middle part of three-stage tunnel across the crack.the joints are not far from two sides of cracks.In order to test the soil pressure of surrounding rock and soil during vibration, 40 miniature earth pressure cells are buried in the top, middle and low layer of surrounding soil and rock model. As can be seen in Figure3, in the aspect of surrounding rock and soil earth pressure.when segmented tunnel is drop in the formation,the surrounding rock and soil earth pressure is almost same with integral tunnel.but after the top disk drop as the cause of motion of cracks, there will be a big difference between added value and overall.The earth pressure of integral tunnel tends to negative after the formation decrease.after the decline of formation, static soil pressure around ground fissures will reduce. While, the segmented tunnel especially the three-stage tunnel added value of soil pressure is mostly postive, after the decline of formation, static soil pressure around ground fissures will increase. Experiments also illustrate the dynamic effects will easily passes to the bottom disc when the top disc is vibrating.as the result of cracks, the dynamic response of bottom disc vibration will have a large attenuation during transfer to the top disc.
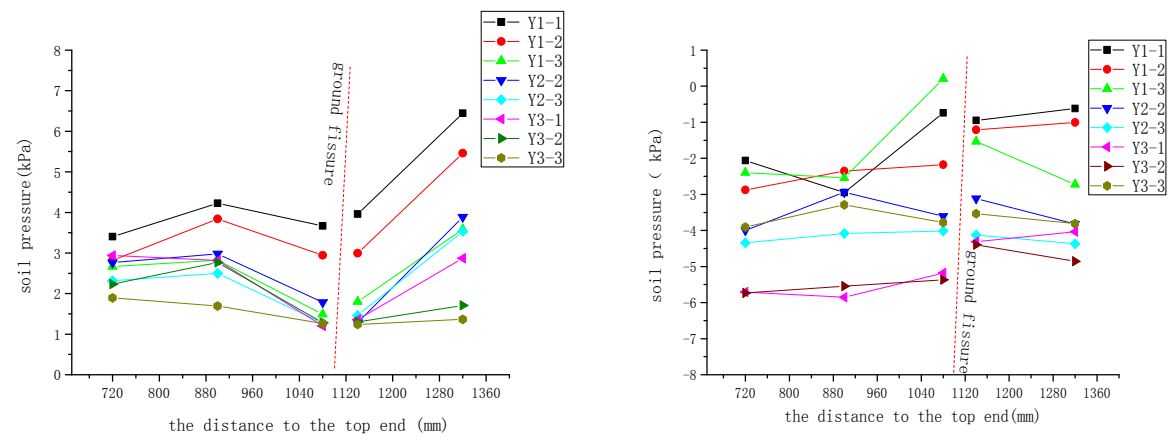

Fig.3 The soil pressure distribution of integral tunnel 


\section{Analysis of surrounding rock and tunnel contact pressure}

In order to test additional contact pressure of lining structure and surrounding rock and soil around the ground fissure,circle hoop of soil pressure sensor are laid on the both side of ground fissures. There are 8 soil pressure sensor on each side. As can be seen from figure 4 (a), when the stratum doesn't drop, Y1-5 and Y2-5 in the dome position increase $6 \sim 7 \mathrm{kPa}$ than static soil pressure as a result of vibration, earth pressure in the dome and the side portions also slightly increases. When the top disc formation decrease $1 \mathrm{~cm}$, the magnitude of change of earth pressure tends to 0 , that is to say,after the formation decrease $1 \mathrm{~cm}$. in the case of vibration generated soil pressure drop and reduce the magnitude of the formation caused considerable soil pressure.After the formation decrease $2 \mathrm{~cm}$, we can see the added value of the contact pressure decreases.it means that the pressure caused by vibration is far lower than the pressure decline caused by formation drops.especially in the dome position, the additional value of contact pressure is $-6 \sim-10 \mathrm{kPa}$.Compare fig. (a) and fig. (b), we can know that the contact pressure distribution of segmented tunnel and overall tunnel is relatively close.But after the top disc formation of ground fissures drop,contact pressure of formation around ground fissures with subway tunnel will decrease.

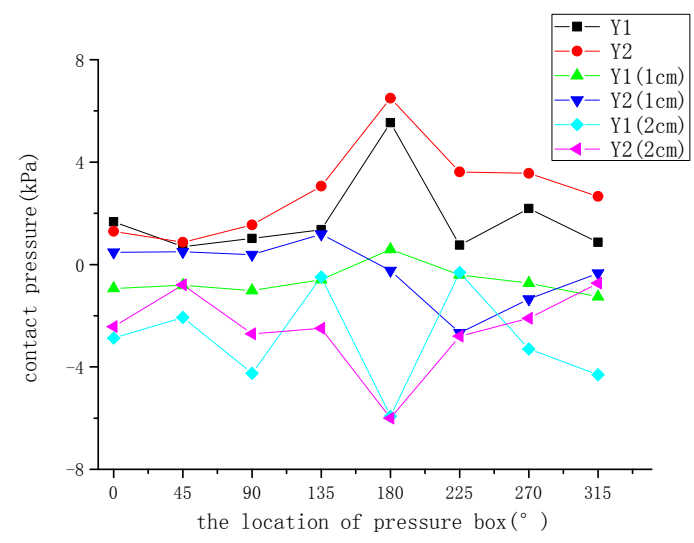

(a)

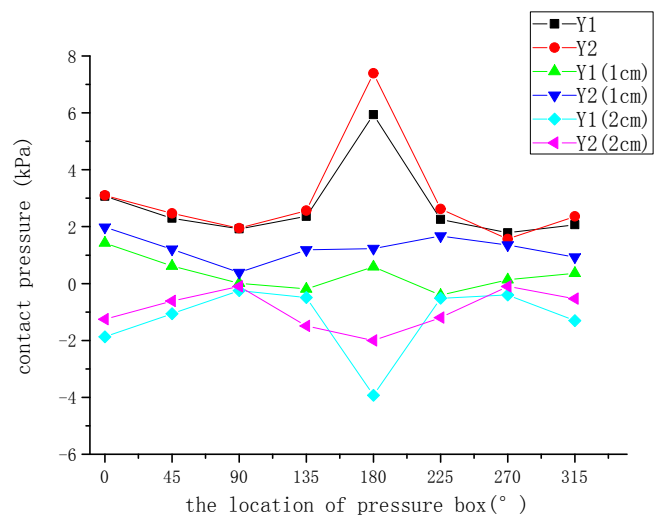

(b)

Fig.4 The soil pressure distribution surrounding the tunnel

\section{Conclusion}

(1) When segmented tunnel formation is not drop, the pressure of surrounding rock and soil is similar with Integral tunnel. However, ground fissures activity leads to decrease of top disc ,the additional value and the overall value of earth pressure are quite different.

(2) The additional value of soil pressure of integral tunnel mostly tends to negative after the formation drops. Integral tunnel soil pressure reduce than static soil pressure. While segmented tunnel especially three-stage tunnel, additional value of soil pressure is mostly positive, this means segmented tunnel soil pressure increase than static soil pressure.

(3) The contact pressure distribution of integral tunnel and segmented tunnel is relatively similar. However, after the top disc drops caused by the motion of ground fissures, Y1 series of soil pressure on the top disc as a result of void formation will have a decline in amount to the Y-2in the bottom disc.

\section{Acknowledgements}

This work was financially supported by Liao cheng university Science Foundation (318051524) and National Natural Science Foundation of China (41502277) . 


\section{References}

[1]MEN Yuming, SHI Yuling. Some Important Scientific Questions in the Research on Xi ' an Ground Fissures[J]. Journal of Earth Sciences and Environment, 2008, 30(2): 172-176.

[2]CHEN Liwei. Study on the Propagation Mechanism of Ground Fissures[D]. Xi'an: Chang'an University, 2007.

[3]YUAN Liqun, LIU Hongjia, MEN Yuming. Research Advances in The Interaction among Stratum-ground Fissure-tunnel under Subway Dynamic Loading[J]. Applied Mechanics and Materials, 2012, 226: 1513-1516.

[4]YUAN Liqun, MEN Yuming, PENG Lingyun, etal. The Similar Principle and Parameters Design of the Model Test for Dynamic Interaction between Metro Tunnel and Stratum[J]. Journal of Disaster Prevention and Mitigation Engineering, 2014, 34 (2) : 180-184.

[5]LI Kailing. Study on the Soil Metro Tunnels Interactions in Ground Fissures Area[D]. Xi'an: Chang'an University, 2012.

[6]ZHANG Ke. Vibration and Settlement of Loess Due to Subway Moving Loads[D]. Xi'an: Xi'an University of Architecture and Technology, 2011.

[7]WANGXin, HAN Xuan, ZHOUHonglei. Study of the Numerical Calculation of Ground Respons e Under Metro Traffic Loading in a Loess Area[J]. Modern Tunnelling Technology, 2014, 51(3) : 152-160. 